\title{
COVID-19: Impact of and on Diabetes
}

Jonathan Schofield (D) - Lalantha Leelarathna $\cdot$ Hood Thabit

Received: May 18, 2020 / Published online: June 6, 2020

(c) The Author(s) 2020

\section{ABSTRACT}

Diabetes has been identified as a pre-existing health condition linked with worse outcomes following coronavirus disease 2019 infection. Here we explore the association between hyperglycaemia and more severe illness, the impact of the pandemic on diabetes service delivery, and the resultant opportunities for innovation.

Keywords: Coronavirus; COVID-19; Diabetes; Hyperglycaemia; Service development

Digital Features To view digital features for this article go to https://doi.org/10.6084/m9.figshare.12326615.

J. Schofield $(\bowtie) \cdot$ L. Leelarathna $\cdot$ H. Thabit Manchester Diabetes Centre, Manchester University Hospitals NHS Foundation Trust, Manchester, UK e-mail: jschofield@doctors.org.uk

J. Schofield · L. Leelarathna $\cdot$ H. Thabit Faculty of Biology Medicine and Health, University of Manchester, Manchester, UK

\section{Key Summary Points}

Diabetes has been linked to worse outcomes following COVID-19 infection.

COVID-19 infection is associated with atypical diabetes presentations.

The current pandemic has required significant service redesign.

The challenge presents opportunities for innovation in diabetes care.

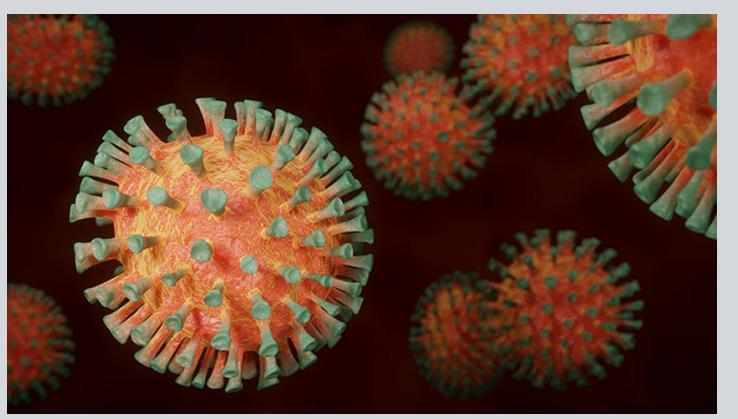




\section{BACKGROUND}

On 31 December 2019, the World Health Organisation (WHO) was informed of a cluster of cases of pneumonia of unknown aetiology in Wuhan City, Hubei Province, China. On 12 January 2020 it was announced that a novel coronavirus had been identified [32]. Coronaviruses are a large family of viruses and although most are responsible for mild disease, such as the common cold, they have also been responsible for more severe disease outbreaks such as severe acute respiratory syndrome (SARS-CoV) in 2002-2003 and Middle East respiratory syndrome (MERS-CoV) in 2012 [38].

Having declared this outbreak a Public Health Emergency of International Concern, WHO named the syndrome caused by this novel coronavirus COVID-19 (coronavirus disease 2019), associated with severe acute respiratory syndrome (SARS-CoV-2) [40]. The clinical spectrum of COVID-19 infection appears remarkably heterogeneous, ranging from very mild symptoms to multi-organ failure and death.

\section{DIABETES AS A PRE-EXISTING HEALTH CONDITION}

There is a perception that people with diabetes are at higher risk both of infection and severe disease from COVID-19 [27]. People with type 1 diabetes who have glucose values close to target may not be at greater risk of developing SARSCoV-2 [23]. Similarly, as evidence accumulates that many people infected with COVID-19 remain asymptomatic [40], it remains uncertain exactly what additional risk pre-existing diabetes poses. Although the risk of contracting COVID-19 may be no greater, viral infections can cause more severe symptoms and complications in people with diabetes [24]. It should also be noted that a number of people with diabetes are at increased risk due to concomitant immunosuppression following solid organ transplantation [39].

Early reports from Wuhan province revealed that those with diabetes mellitus were overrepresented among the most severely ill patients with COVID-19 $[16,19]$. This finding is in keeping with an analysis of people hospitalised by SARS-CoV, where even transient hyperglycaemia was associated with increased mortality [41]. Diabetes was also identified as being one of the most common comorbidities in a case series of 5700 patients in the New York City area requiring hospitalisation for SARSCoV-2 [35].

Proposed mechanisms to explain the observed association between diabetes and SARS-CoV-2 include chronic inflammation, an impaired immune response, increased coagulation activity, and direct pancreatic islet cell injury [20]. Well-controlled diabetes is associated with better outcomes than poorly controlled diabetes [46], but even short-term hyperglycaemia can stun the innate immune system [22]. Emerging evidence suggests that in the context of COVID-19, acute hyperglycaemia may be a greater risk factor for adverse outcomes than a diagnosis of diabetes [6].

The SARS-CoV-2 pandemic highlights the importance of understanding shared disease pathophysiology, particularly where it might inform therapeutic choices for people with diabetes. Emerging data suggests that SARSCoV-2 is also common in patients with hypertension and cardiovascular disease, although the prevalence rate has varied in different studies as well as globally [37]. Obesity is also a risk factor for more severe COVID-19-related illness [14]. In a meta-analysis of eight studies $(n=46,248)$ the odds ratio of severe SARS-CoV2 was not significantly higher in patients with diabetes, unlike hypertension and cardiovascular disease [42]. It may therefore be more appropriate to say that complications and comorbidities linked to diabetes are associated with a higher mortality rate than the presence of diabetes per se [17]. The apparent association with worse outcomes might also reflect the higher prevalence of type 2 diabetes in older people [7].

Angiotensin-converting enzyme 2 (ACE2) is now established as the SARS-CoV receptor but with conflicting data as to its translational relevance [43]. A role for ACE2 in explaining the association between cardiovascular disease in diabetes and SARS-CoV-2 has been suggested. 
ACE2 expression is reduced in people with diabetes possibly as a result of glycosylation, but expression is increased in patients taking ACE inhibitors or angiotensin receptor blockers [30]. Speculation around possible adverse or protective effects has not proven helpful, and people prescribed ACE inhibitor drugs and angiotensin receptor blockers have been advised to continue taking them [15]. Membrane-associated dipeptidyl peptidase 4 (DPP4) also functions as a coronavirus receptor [33] but there is currently no evidence to support clinically meaningful effects on immune function through DPP4 inhibition [14].

Acute viral infection has previously been linked to the rapid development of transient insulin resistance [36]. Infection with COVID19 is also generally associated with an increased insulin requirement [17].

There are many unanswered questions regarding the course of clinical recovery following SARS-CoV-2, and it is of interest that diabetes appears to be associated with increased time for viral clearance [10].

\section{SERVICE DESIGN}

COVID-19 will also impact on the health of people with diabetes who are not infected with the virus but find that their clinical care is compromised because of service disruption. Clinical teams have been challenged to fulfil their general responsibilities and prioritise acute care in relation to COVID-19 whilst ensuring that essential diabetes care continues [24].

People with diabetes continue to require emergency admissions and medical management and specialists have an important role to play expediting treatment and minimising length of stay [29]. Many inpatient diabetes services have looked to increase their capacity in recognition of the reported association between diabetes and hospitalisation with COVID-19 infection, and to mitigate against the impact of a potentially reduced workforce.

Direction has been given to minimise outpatient attendances, with movement towards virtual consultations, including support for those recently discharged from hospital to reduce the risk of readmission. Community services should not underestimate the importance of their contributions to maintaining diabetes care. Triaging of clinic lists supports the identification of those patients who might still require face-to-face review. Specialist teams should also acknowledge that clinic postponement will equate to cancellation in a proportion of cases. Traditional reliance on biochemical parameters to inform management decisions in diabetes does mean that access to phlebotomy services must also be considered where useful information cannot be obtained from shared data [29].

Secondary care services that may need to continue at close to full capacity include multidisciplinary diabetic foot services and pregnancy and diabetes services. The International Working Group on the Diabetic Foot has looked to remind clinicians that most patients with diabetic foot disease do not need to be hospitalised [21]. Inpatient teams should also ensure that acute foot infection is not missed as nonspecific symptoms are attributed to SARS-CoV2 . The precautionary identification of pregnant women as being at higher risk of severe COVID19-related illness has led to the rapid implementation of remote antenatal care, including diabetes management. Modifications have also been made to the screening pathway for gestational diabetes [34].

\section{CHALLENGES}

National and locally driven crisis management plans must look to manage anxiety, about the health of clinical staff and the people they care for, but also around redeployment and service reconfiguration. Redeployment and new ways of working will inevitably impact the education and training of healthcare providers in diabetes management, and alternative approaches will need to be adopted.

The longer-term healthcare impact of social lockdown may not be apparent for some time. In the short term, interruption of daily activities, including diet and exercise, may have a significant impact on glucose control, as may anxiety and sleep disturbance. Structured 
diabetes education has been recommended by the National Institute for Health and Care Excellence (NICE) since 2003 [13]. Much of this is delivered through group education, which has been suspended, and may not be able to restart for some time.

While technology companies have been quick to reassure users around their supply chains [3], centres where diabetes technology supplies have traditionally been delivered to the clinical site rather than directly to users have had to recognise the additional risk this carries. Companies have agreed to extend warranties for insulin pumps but have also offered remote pump upgrade services where appropriate.

Initial insights suggested that COVID-19 infection increased the risk of emergency states of hyperglycaemia with ketones, diabetic ketoacidosis (DKA) and hyperosmolar hyperglycaemic state [28]. These atypical presentations have challenged inpatient diabetes teams and led to some anxiety around the prescription of sodium-glucose co-transporter 2 (SGLT2) inhibitors. It remains important that people with both type 1 and type 2 diabetes follow the sick day rules should they become unwell from any illness.

SGLT2 inhibitors have significant cardiovascular and renal benefits in people with type 2 diabetes but are associated with a small but increased risk of ketoacidosis. There are to date only anecdotal reports of ketoacidosis in patients with SARS-CoV-2 taking SGLT2 inhibitors, but they should be suspended in any acute medical admission, vomiting or dehydration [2]. Metformin should also be used with caution in unwell patients. Interestingly metformin has been proposed to have immunomodulatory actions [8]. Glucagon-like peptide 1 (GLP1) receptor agonists also exert anti-inflammatory actions and may even attenuate pulmonary inflammation [44]. Although the short-term safety of GLP1 agonists has been demonstrated in critically unwell patients [26] there is still insufficient experience to make recommendations around their use in patients with SARS-CoV-2.

With perhaps the exception of SGLT2 inhibitors, most patients with mild COVID-19 symptoms and normal oral intake can continue their usual anti-hyperglycaemic medications. Review of glucose-lowering medications should be carefully considered given the possible implications of increased glycaemic variability [9]. Insulin has been used most extensively in the management of hyperglycaemia in critically ill patients [14]. Insulin also exerts anti-inflammatory actions [18].

Challenges in fluid replacement in DKA due to concerns over acute respiratory distress syndrome and with the availability of infusion pumps for intravenous insulin administration have also been reported [28]. Here subcutaneous insulin regimes may prove helpful in the management of hyperglycaemia where tissue perfusion has not been compromised.

Analysis of capillary blood glucose tests in patients with SARS-CoV-2 admitted to a medical centre in Wuhan suggested suboptimal adherence to current best practice for the management of hyperglycaemia [45]. This is perhaps not surprising given the pressure on healthcare systems, and the increased exposure of healthcare staff associated with frequent capillary blood glucose monitoring and adjustment of insulin infusions, but emerging evidence suggests that good glycaemic control is associated with improved outcomes in patients hospitalised with SARS-CoV-2 [46]. Automated closed-loop insulin-delivery systems have been proven safe and effective in non-critical care environments [4]. The feasibility of fully automated closed-loop glucose control has also been studied in critical illness [25] and may be an option. The finding that patients admitted with SARS-CoV-2 often developed acute hyperglycaemia following hospitalisation suggests that an opportunity exists for more interventional glycaemic management [6].

\section{OPPORTUNITIES}

The prevalence of diabetes or stress hyperglycaemia in people hospitalised with COVID-19 infection and recognition that improved glycaemic control might improve outcomes and reduce length of stay in patients with SARSCoV-2 have underlined the importance of specialist inpatient diabetes teams to acute care. 
The current pandemic has also highlighted opportunities for continuing and expanding innovations in the delivery of diabetes care, through virtual consultations between healthcare providers and people with diabetes, and the use of diabetes technology [14]. Crisis management has created unprecedented interest in remote care from both patients and providers, and removed many long-standing regulatory barriers. The US Food and Drug Administration has also allowed the use of personal blood glucose meters and continuous glucose monitoring devices in hospital for the duration of the pandemic $[1,12]$.

Virtual consultations might also support people with diabetes to be seen by the 'right person at the right time' instead of waiting months between routine clinic appointments. This might be a physician, specialist nurse/diabetes educator, dietician or clinical psychologist [31].

While group face-to-face structured diabetes education may not be possible for some time, there are opportunities to pilot alternative forms of delivery. Patient-led remote models of structured diabetes education have been reported to improve both uptake and clinical outcomes. The digital version of DESMOND, an evidence-based type 2 diabetes structured education programme, was made free to everyone with type 2 diabetes in the UK in April 2020 [11]. BERTIE Online offers fully remote diabetes structured education for people with type 1 diabetes [5].

Enforced service redesign through this pandemic will also enable other innovations in diabetes care, which might only become apparent over the coming months. This article is based on previously conducted studies and does not contain any studies with human participants or animals performed by any of the authors.

\section{ACKNOWLEDGEMENTS}

Funding. No funding or sponsorship was received for publication of this article.
Authorship. All named authors meet the International Committee of Medical Journal Editors (ICMJE) criteria for authorship for this article, take responsibility for the integrity of the work as a whole, and have given their approval for this version to be published.

Disclosures. Jonathan Schofield is a member of the journal's Editorial Board. Lalantha Leelarathna and Hood Thabit have nothing to disclose.

Compliance with Ethics Guidelines. This article is based on previously conducted studies and does not contain any studies with human participants or animals performed by any of the authors.

Open Access. This article is licensed under a Creative Commons Attribution-NonCommercial 4.0 International License, which permits any non-commercial use, sharing, adaptation, distribution and reproduction in any medium or format, as long as you give appropriate credit to the original author(s) and the source, provide a link to the Creative Commons licence, and indicate if changes were made. The images or other third party material in this article are included in the article's Creative Commons licence, unless indicated otherwise in a credit line to the material. If material is not included in the article's Creative Commons licence and your intended use is not permitted by statutory regulation or exceeds the permitted use, you will need to obtain permission directly from the copyright holder. To view a copy of this licence, visit http://creativecommons.org/licenses/by$\mathrm{nc} / 4.0 /$.

\section{REFERENCES}

1. Abbott. Abbott's Freestyle Libre 14 Day System now available in US for hospitalized patients with diabetes during COVID-19 pandemic. 2020. https:// abbott.mediaroom.com/2020-04-08-Abbotts-FreeSty le-R-Libre-14-Day-System-Now-Available-in-U-S-forHospitalized-Patients-with-Diabetes-During-COVID19-Pandemic. Accessed 19 Apr 2020. 
2. ABCD. SGLT-2 inhibitors in people with type 2 diabetes. 2020. https://abcd.care/sites/abcd.care/ files/site_uploads/Resources/Position-Papers/SGLT2inhibitors-ABCD.pdf. Accessed 16 Apr 2020.

3. ABHI. Statement on uninterrupted diabetes supplies. 2020. https://www.abhi.org.uk/media/2505/ statement-on-diabetes-supplies.pdf. Accessed 13 Apr 2020.

4. Bally L, Thabit H, Hartnell S, et al. Closed-loop insulin delivery for glycemic control in noncritical care. N Engl J Med. 2018;379:547-56.

5. BERTIE. BERTIE Online. 2016. https://www. bertieonline.org.uk. Accessed 10 May 2020.

6. Bode B, Garrett V, Messler J, et al. Glycemic characteristics and clinical outcomes of COVID-19 patients hospitalized in the United States. J Diabetes Sci Technol. 2020. https://doi.org/10.1177/ 1932296820924469.

7. Bornstein SR, Rubino F, Khunti K, et al. Practical recommendations for the management of diabetes in patients with COVID-19. Lancet Diabetes Endocrinol. 2020. https://doi.org/10.1016/S22138587(20)30152-2.

8. Cameron AR, et al. Anti-inflammatory effects of metformin irrespective of diabetes status. Circ Res. 2016;119(5):652-65.

9. Ceriello A, Monnier L, Owens D. Glycaemic variability in diabetes: clinical and therapeutic implications. Lancet Diabetes Endocrinol. 2019;7(3): 221-30.

10. Chen $\mathrm{X}, \mathrm{Hu} \mathrm{W}$, Ling $\mathrm{J}$, et al. Hypertension and diabetes delay the viral clearance in COVID-19 patients. 2020. https://www.medrxiv.org/content/ 10.1101/2020.03.22.20040774v1. Accessed 19 Apr 2020.

11. Desmond. MyDesmond made free amid COVID-19 pandemic. 2020. https://www.desmond-project. org.uk/mydesmond-made-free-amid-covid-19pandemic/. Accessed 10 May 2020.

12. Dexcom. Fact sheet for healthcare providers: use of dexcom continuous glucose monitoring systems during the COVID-19 pandemic. 2020. https:// www.dexcom.com/hospitalfacts. Accessed 13 Apr 2020.

13. Diabetes UK. Quality diabetes education for all: a short guide for commissioners. 2015. https:// diabetes-resources-production.s3-eu-west-1.amazon aws.com/diabetes-storage/migration/pdf/Diabetes $\%$ 2520UK\%2520-\%2520Quality\%2520diabetes\%2520 education $\% 2520$ for $\% 2520$ all $\% 2 \mathrm{C} \% 2520 \mathrm{a} \% 2520$ sho rt\%2520guide\%2520for\%2520commissioners\%2520
\%28November\%25202015\%29.pdf. Accessed 10 May 2020.

14. Drucker DJ. Coronavirus infections and type 2 diabetes-shared pathways with therapeutic implications. Endocr Rev. 2020;41(3):bnaa011.

15. European Society of Cardiology. Position statement of the ESC council on hypertension on ACE-inhibitors and angiotensin receptor blockers. 2020. https://www.escardio.org/Councils/Council-on-Hyp ertension-(CHT)/News/position-statement-of-the-esccouncil-on-hypertension-on-ace-inhibitors-and-ang. Accessed 13 Mar 2020.

16. Guan WJ, et al. Clinical characteristics of coronavirus disease 2019 in China. N Engl J Med. 2020;382(18):1708-20.

17. Guo W, Li M, Dong Y, et al. Diabetes is a risk factor for the progression and prognosis of COVID-19. Diabetes Metab Res Rev. 2020. https://doi.org/10. 1002/dmrr.3319.

18. Hansen $\mathrm{TK}$, et al. Intensive insulin therapy exerts antiinflammatory effects in critically ill patients and counteracts the adverse effect of low mannosebinding lectin levels. J Clin Endocrinol Metab. 2003;88(3):1082-8.

19. Huang C, et al. Clinical features of patients infected with 2019 novel coronavirus in Wuhan, China. Lancet. 2020;395(10223):497-506.

20. Hussain A, Bhowmik B, Moreira NCV. COVID-19 and diabetes: knowledge in progress. Diabetes Res Clin Pract. 2020;162:108142.

21. IWGDF. COVID-19 and diabetic foot disease. 2020. https://iwgdfguidelines.org/covid-19/. Accessed 16 Apr 2020.

22. Jafar N, Edriss H, Nugent K. The effect of short-term hyperglycemia on the innate immune system. Am J Med Sci. 2016;351(2):201-11.

23. JDRF. Coronavirus (COVID-19)-information for people living with type 1 diabetes. 2020. https:// jdrf.org.uk/coronavirus-covid-19-information-forpeople-living-with-type-1-diabetes/. Accessed 17 Apr 2020.

24. Kaiser UB, Mirmira RG, Stewart PM. Our response to COVID-19 as endocrinologists and diabetologists. J Clin Endocrinol Metab. 2020;105(5):1299-1301.

25. Leelarathna L, et al. Feasibility of fully automated closed-loop glucose control using continuous subcutaneous measurements in critical illness: a randomized controlled trial. Crit Care. 2013;17(4): R159. 
26. Lee MY, et al. The effect of exogenous glucose-dependent insulinotropic polypeptide in combination with glucagon-like peptide- 1 on glycemia in the critically ill. Diabetes Care. 2013;36(10):3333-6.

27. Ma RCW, Holt RIG. COVID-19 and diabetes. Diabet Med. 2020;37(5):723-5.

28. National Inpatient COVID-19 Response Team. COncise adVice on Inpatient Diabetes (COVID:Diabetes): FRONT DOOR GUIDANCE. 2020. https:// www.diabetes.org.uk/resources-s3/public/2020-04/ COvID_Front_Door_v1.0.pdf. Accessed 17 Apr 2020 .

29. NHS England. Clinical guide for the management of people with diabetes during the coronavirus pandemic. 2020. https://www.england.nhs.uk/ coronavirus/wp-content/uploads/sites/52/2020/03/ speciality-guide-diabetes-19-march-v2-updated.pdf. Accessed 17 Apr 2020.

30. Pal R, Bhansali A. COVID-19, diabetes mellitus and ACE2: the conundrum. Diabetes Res Clin Pract. 2020;162:108132.

31. Peters AL, Garg S. The silver lining to COVID-19: avoiding diabetic ketoacidosis admissions with telehealth. Diabetes Technol Ther. 2020. https:// doi.org/10.1089/dia.2020.0187.

32. Public Health England. COVID-19: epidemiology, virology and clinical features. 2020. https://www. gov.uk/government/publications/wuhan-novel-coro navirus-background-information/wuhan-novel-coro navirus-epidemiology-virology-and-clinical-features. Accessed 19 Apr 2020.

33. Raj VS, et al. Dipeptidyl peptidase 4 is a functional receptor for the emerging human coronavirusEMC. Nature. 2013;495(7440):251-4.

34. RCOG. Guidance for maternal medicine services in the evolving coronavirus (COVID-19) pandemic. 2020. https://www.rcog.org.uk/globalassets/docu ments/guidelines/2020-04-09-guidance-for-maternalmedicine-services-in-the-evolving-coronavirus-covid19-pandemic.pdf. Accessed 10 Apr 2020.

35. Richardson S, Hirsch JS, Narasimhan M, et al. Presenting characteristics, comorbidities, and outcomes among 5700 patients hospitalized with COVID-19 in the New York City Area. JAMA. 2020. https://doi.org/10.1001/jama.2020.6775.
36. Sestan M, et al. Virus-induced interferon- $\gamma$ causes insulin resistance in skeletal muscle and derails glycemic control in obesity. Immunity. 2018;49(1): 164-77.

37. Singh AK, Gupta R, Ghosh A, Misra A. Diabetes in COVID-19: prevalence, pathophysiology, prognosis and practical considerations. Diabetes Metab Syndr. 2020;14(4):303-10.

38. Song $\mathrm{Z}, \mathrm{Xu} \mathrm{Y}, \mathrm{Bao} \mathrm{L}$, et al. From SARS to MERS. Thrusting coronaviruses into the spotlight. Viruses. 2019;11(1):59.

39. Weinrauch LA, et al. Infection and malignancy outweigh cardiovascular mortality in kidney transplant recipients: post hoc analysis of the FAVORIT trial. Am J Med. 2018;131(2):165-72.

40. World Health Organization. Rolling updates on coronavirus disease (COVID-19). 2020. https:// www.who.int/emergencies/diseases/novelcoronavirus-2019/events-as-they-happen. Accessed 19 Apr 2020.

41. Yang JK, Lin SS, Ji XJ, Guo LM. Binding of SARS coronavirus to its receptor damages islets and causes acute diabetes. Acta Diabetol. 2010;47(3):193-9.

42. Yang J, Zheng Y, Gou X, et al. Prevalence of comorbidities and its effects in patients infected with SARS-CoV-2: a systematic review and metaanalysis. Int J Infect Dis. 2020;94:91-5. https://doi. org/10.1016/j.ijid.2020.03.017.

43. Yan R, et al. Structural basis for the recognition of SARS-CoV-2 by full length human ACE2. Science. 2020;367(6485):1444-8.

44. Zhou F, et al. Liraglutide attenuates lipopolysaccharide-induced acute lung injury in mice. Eur J Pharmacol. 2016;791:735-40.

45. Zhou J, Tan J. Diabetes patients with COVID-19 need better blood glucose management in Wuhan, China. Metabolism. 2020;107:154216.

46. Zhu L, She ZG, Cheng X, et al. Association of blood glucose control and outcomes in patients with COVID-19 and pre-existing type 2 diabetes. Cell Metab. 2020. https://doi.org/10.1016/j.cmet.2020. 04.021 . 